\title{
Tras los pasos del mitayo: la sacralización del espacio en los corregimientos de Pacajes y Omasuyos (1570-1650)
}

À la poursuite du mitayo: la sacralisation de l'espace dans les corregimientos de Pacajes et Omasuyos (1570-1650)

On the track of the mitayo: the sacralization of space in the Pacajes and Omasuyos corregimientos (1570-1650)

\section{Ariel J. Morrone}

\section{(2) OpenEdition}

Journals

Edición electrónica

URL: http://journals.openedition.org/bifea/7408

DOI: $10.4000 /$ bifea.7408

ISSN: 2076-5827

Editor

Institut Français d'Études Andines

Edición impresa

Fecha de publicación: 1 abril 2015

Paginación: 91-116

ISSN: 0303-7495

Referencia electrónica

Ariel J. Morrone, «Tras los pasos del mitayo: la sacralización del espacio en los corregimientos de Pacajes y Omasuyos (1570-1650) », Bulletin de I'Institut français d'études andines [En línea], 44 (1) I 2015, Publicado el 08 mayo 2015, consultado el 06 noviembre 2020. URL : http:// journals.openedition.org/bifea/7408; DOI : https://doi.org/10.4000/bifea.7408

\section{(c)}

Les contenus du Bulletin de l'Institut français d'études andines sont mis à disposition selon les termes de la licence Creative Commons Attribution - Pas d'Utilisation Commerciale - Pas de Modification 4.0 International. 


\title{
Tras los pasos del mitayo: la sacralización del espacio en los corregimientos de Pacajes y Omasuyos (1570-1650)
}

\author{
Ariel J. Morrone*
}

\section{Resumen}

Este trabajo propone que el traslado de los mitayos desde sus pueblos de reducción hasta las minas de Potosí se realizaba a través de caminos y espacios rituales. Según Martti Pärssinen, existió un sistema de linderos impuestos por el poder incaico en el territorio de la jefatura pakaxa, emplazada en la cuenca meridional del lago Titicaca (actual departamento de La Paz, Bolivia). A partir de esta sugerencia, reconstruimos esos «caminos de la mita», auspiciados por los líderes étnicos, que partían de los pueblos de reducción hacia espacios de congregación, para confluir en Potosí y los cerros aledaños, importantes centros de adoración surandinos. Sin negar el carácter explotativo de la mita potosina, ahondamos en otras prácticas asociadas a la misma, para recuperar algunas pautas de la religiosidad nativa, cuyas huellas son elusivas en la documentación colonial.

Palabras clave: liderazgo étnico, legitimidad, territorialidad, espacios sacralizados, religiosidad, memoria colectiva

\section{À la poursuite du mitayo: la sacralisation de l'espace dans les corregimientos de Pacajes et Omasuyos (1570-1650)}

\section{Résumé}

Cet article propose que le déplacement des mitayos de leurs pueblos de reducción (villages) jusqu'aux mines de Potosí se faisait grâce à des routes et des espaces rituels. Selon Martti Pärssinen, il existait un système de limites imposées par le pouvoir inca dans le territoire de la chefferie pakaxa, situé dans le bassin méridional du lac Titicaca (actuel départament de La Paz, Bolivie). À partir de cette hypothèse,

* Programa de Historia de América Latina (Prohal), Instituto de Historia Argentina y Americana «Dr. Emilio Ravignani», Facultad de Filosofía y Letras, Universidad de Buenos Aires. Dirección: 25 de Mayo 221,2을 Piso, Buenos Aires, Argentina. E-mail: arielmorri@yahoo.com.ar 
I'article reconstruit ces «chemins de la mita», contrôlés par les leaders ethniques, qui partaient des pueblos de reducción jusqu'aux espaces de rassemblement, pour confluer vers Potosí et les collines environnantes, importants centres d'adoration des Andes du sud. Sans nier le caractère exploratoire de la mita potosina, l'auteur se sert d'autres pratiques qui lui sont associées, afin de comprendre certaines tendances de la religion indigène, dont les traces sont difficiles à cerner dans les documents coloniaux.

Mots-clés : chefferie ethnique, légitimité, territorialité, espaces sacrés, religiosité, mémoire collective

\title{
On the track of the mitayo: the sacralization of space in the Pacajes and Omasuyos corregimientos (1570-1650)
}

\begin{abstract}
This article argues that the transfer of mitayos from their pueblos de reducción to the Potosí mines was done using ritual paths and spaces. According to Martti Pärssinen, there was a boundary system imposed by the Inkas in the core area of Pakaxa chiefdom in the southern basin of Titicaca lake (currently the Department of La Paz, Bolivia). From this suggestion, we reconstruct those "mita pathways", overseen by ethnic leaders, which departed from the pueblos de reducción to local congregations, and ultimately converging on Potosí and the surrounding hills that were major centers of worship in the South Andes. Without denying the exploitative nature of the mita of Potosi, we dig deep into associated practices, in order to recover some patterns of native religiosity, whose traces are elusive in colonial documents.
\end{abstract}

Key words: ethnic leadership, legitimacy, territoriality, sacred spaces, religiosity, collective memory

A partir del gobierno del virrey don Francisco de Toledo (1569-1581) asistimos a una verdadera sistematización de políticas estatales que derivaron en la definitiva consolidación del poder colonial en el virreinato del Perú. Entre sus reformas, la organización de la mita minera para la explotación del Cerro Rico de Potosí fue una de las claves que garantizaron la reproducción de la economía surandina y el drenaje de riquezas argentíferas hacia las desfalcadas arcas metropolitanas. Para la provisión de la mano de obra nativa destinada a la extracción del metal, el gobierno colonial recaló en las figuras de autoridad nativas (los kuraka o caciques, en general), encargados del reclutamiento de mitayos a partir de los colectivos étnicos que lideraban. Estas nuevas funciones redundaron en un reposicionamiento de los caciques, quienes a partir de entonces fueron los principales responsables del cumplimiento de las cuotas mitayas (Sánchez Albornoz, 1978; Cole, 1985; Choque Canqui, 1993).

Para implementar esta reforma, el territorio surandino fue reorganizado en las llamadas «capitanías de mita», jurisdicciones que en gran medida tomaron como base los territorios de las jefaturas prehispánicas. De este modo, cada capitanía recaía anualmente en un líder étnico que debía garantizar la leva mitaya del año siguiente, haciéndose cargo de los costos. Nuestro trabajo toma distancia de las implicancias «materiales» de la explotación minera, para tratar de evaluar hasta qué punto la mita potosina y la participación de los caciques como capitanes 
de mita habilitaron la continuidad de ciertas prácticas asociadas a la religiosidad nativa, expresadas específicamente en torno a los cultos mineros. En esta instancia, los líderes étnicos jugaron un papel articulador que queremos destacar, sobre todo en lo atinente a su legitimidad interna, es decir, aquella emanada de sus ayllu, unidades parentales de base.

Nuestro trabajo se recorta espacialmente a los corregimientos de Pacajes y Omasuyos, emplazados en los márgenes meridional y oriental del lago Titicaca, respectivamente. Ambas jurisdicciones administrativas, dependientes de la ciudad de La Paz, englobaban repartimientos de indios que habían formado parte, en tiempos prehispánicos, de la jefatura pakaxa, sociedad de base agropastoril incorporada al Estado incaico desde mediados del siglo XV. Los pakaxa ejercían una territorialidad discontinua aunque organizada en torno a asentamientos principales (llamados marka) en los que residían las autoridades étnicas. Esta configuración territorial fue altamente modificada por la invasión española, la distribución de la población nativa, a partir de la formación de los repartimientos de indios en la década de 1540, y el proceso de concentración forzada de la población, a través de la reducción a pueblos de indios en la década de 1570 (Choque Canqui, 1993; Morrone, 2012).

Proponemos analizar el liderazgo étnico bajo el prisma de la religiosidad, ya que la misma constituye un componente central para comprender el liderazgo en las sociedades andinas, en tanto las autoridades étnicas encarnaron un conjunto de simbolismos y representaciones del poder que se remontan al pasado prehispánico y se resignificaron en el contexto colonial y cristiano (Taylor, 19741976; Martínez Cereceda, 1995; Estenssoro Fuchs, 2003; Ramírez, 2005; Ramos, 2010). La legitimidad interna de los líderes étnicos no solo contaba con soportes «materiales»: es nuestra hipótesis que debían garantizar además cierta continuidad de prácticas religiosas en un contexto de creciente cristianización de la población nativa. Cuánto había permanecido de la antigua religiosidad y cómo interactuaron los dos sistemas de creencias son interrogantes que nos llevan a reflexionar en torno a la dimensión simbólica de la autoridad indígena.

La tensión entre prácticas religiosas prehispánicas que no desaparecieron y la progresiva incorporación de elementos cristianos repercutió en los criterios de legitimación de los caciques coloniales. Así como tuvieron que enfrentar el desafío de pugnar por el acceso a recursos, la religiosidad también devino en arena de conflicto; en efecto, incluyó un conjunto de recursos simbólicos que entraron en disputa a partir de la invasión hispánica y la consolidación del dominio colonial (Bourdieu, 1982 [1976]). En este trabajo nos detendremos en una dimensión territorial de la religiosidad, para lo cual indagaremos en la sacralización de algunos espacios asociados a la mita potosina y en el rol de las autoridades étnicas en este contexto. 


\section{CLAVES ANALÍTICAS: RELIGIOSIDAD, LEGITIMIDAD Y TERRITORIALIDAD}

¿Qué estrategias argumentativas diseñamos al ingresar en un tópico para el que las fuentes son por demás elusivas, cuando no refractarias? En tanto operación historiadora, cada hipótesis, afirmación o propuesta debe sustentarse en evidencia empírica, siendo la documentación escrita el recurso «clásico». Ahora bien, existen prácticas, actitudes, simbolismos y pautas de relación social que no quedan expresadas por escrito; sobre todo, en un sistema escriturario como la documentación colonial, materialización concreta del dominio político de una minoría conquistadora sobre las mayorías conquistadas. De este modo, disponemos de limitada documentación escrita para indagar en la religiosidad nativa y en los criterios simbólicos de la legitimidad de los líderes étnicos. Incluso, las fuentes que presentamos aquí demandaron un arduo trabajo para leer, siempre entre líneas, algunas huellas del problema a abordar.

La investigación nos llevó por los senderos teóricos de la Antropología y la Geografía. La clave política de ambos campos disciplinares nos ofrece perspectivas, herramientas e interrogantes por demás fructíferos. Sostenemos que los mecanismos por los cuales los líderes étnicos concitaron y construyeron su legitimidad interna estuvieron anclados en su capacidad de (re)presentarse como vínculo entre el orden social y el orden cosmológico. Así como reconfiguraron sus prácticas sociales en el contexto de la mercantilización de la economía surandina, pasado el «traumatismo de la conquista», también reconvirtieron su lugar en el esquema interpretativo del mundo y del cosmos, mientras iniciaban, al mismo tiempo, un proceso, no sin conflictos, hacia la conversión cristiana. Recurrieron, según creemos, a la memoria colectiva y la territorialidad para mantener esa posición de intermediación simbólica (Halbwachs, 1950: 35-79; BouysseCassagne, 2000; Morrone, 2010a).

A nuestro entender, el espacio y la ritualidad fueron, en tanto dispositivos mnemónicos, herramientas de las cuales los líderes étnicos bien pudieron echar mano para resolver la yuxtaposición de sistemas de creencias. Nos movemos aquí en tres niveles. En primer lugar, los cultos nativos preincaicos, cotidianos, centrados en la adoración a los antepasados, los ciclos del cultivo y del ganado, a nivel de las unidades domésticas. En segundo lugar, el culto imperial, de menor profundidad temporal, pero que impactó en la organización política de las sociedades incorporadas al Tawantinsuyu porque también se trató de una conquista ritual. Finalmente, la progresiva imposición del cristianismo, proceso para nada lineal, cuyas imbricaciones con los sistemas previos redundó en condensaciones, desplazamientos, yuxtaposiciones de prácticas religiosas (Farris, 1992 [1984]; Duviols, 1986; MacCormack, 1991; Decoster, 2002).

Asimismo, la territorialidad jugó un rol clave en las identificaciones colectivas y en la validación de la legitimidad de las autoridades étnicas. Derivado de prácticas sociales activas, el territorio es el resultado de luchas por el control de ciertos recursos, personas, relaciones, símbolos; el territorio habilita el 
control de zonas de producción, que hacen al sustento material de las unidades domésticas. Acaso este aspecto «tangible» del análisis territorial resulte más perceptible desde una perspectiva occidental-moderna. Pero el territorio también se define por aspectos menos tangibles, más abstractos, ya que constituye una plataforma para la identificación étnica, política y social (Carmagnani, 1988: 4950). Simultáneamente, el territorio configura la ritualidad y es sacralizado por ella. Esta relación de interdependencia entre el espacio y las prácticas sociales estructura una geografía sagrada, reconstituida a partir de los rituales, muchas veces evanescentes en la documentación, pero que diseñan una cartografía para comprender las coordenadas simbólicas de la religiosidad nativa (Acuto, 1999).

Nuestra propuesta se orienta a pensar la territorialidad de los cultos como una forma de materializar el vínculo entre el orden cosmológico y el orden social. En las figuras de liderazgo étnico convergieron, entonces, ambos planos de la territorialidad: uno más vinculado a lo material, otro a lo inmaterial; aunque, en realidad, esa cesura solo es operativa a fines analíticos. Difícilmente podamos aceptar que ambas esferas estuvieran tan claramente delimitadas en la sociedad que estudiamos. Así, la conexión entre las sociedades premodernas y el espacio que ocuparon fue extremadamente estrecha, no solo por la familiaridad, sino porque sus miembros se pensaban a sí mismos y a ese espacio como orgánica e incluso espiritualmente vinculados (Sack, 1986: 58).

Los sistemas políticos premodernos manejaron una territorialidad flexible y permeable, cercanos a un modelo de Estado jurisdiccional, organización política jerarquizada en torno a redes de alianzas en constante negociación, basado más en la administración de personas que en el control efectivo de un área geográfica estrictamente delimitada (Ramírez, 2005: 32). Análogamente podemos pensar en espacios culturales y religiosos, de límites difusos, que se fueron transformando al calor de los cambios políticos, produciéndose, en efecto, superposiciones de elementos correspondientes a distintos registros de religiosidad (Amselle, 1985; Cruz, 2009). Hacia esos espacios de culto, articulados en torno a una geografía sagrada, orientamos nuestra atención en este trabajo.

\section{LOS CAMINOS DE LA MITA: ENTRE POSTAS Y MEMORIAS}

La asociación entre espacios sagrados, memoria colectiva y legitimidad de los líderes étnicos puede pensarse en el contexto de la mita potosina, con motivo del auspicio y mantenimiento, por parte de ciertos caciques, de ciertos cultos mineros que habrían continuado vigentes hasta bien entrado el siglo XVII (Bouysse-Cassagne 2005; Platt, Bouysse-Cassagne \& Harris, 2006: 164; cf. Ramírez del Águila, 1978 [1639]: 132). Así, en trabajos anteriores analizamos las trayectorias de los caciques del pueblo de Jesús de Machaca (corregimiento de Pacajes), quienes ocuparon el cargo de capitán de mita en reiteradas oportunidades a lo largo del siglo XVII. Don Gabriel Fernández Guarachi, cacique principal (1620-1673), lo ejerció en once ocasiones, las últimas tres de ellas junto a su sobrino y sucesor, don Pedro Fernández Guarachi (1673-1681) (Morrone, 2010a; 2010b; cf. Choque Canqui, 
2003: 195-196)1. En esta oportunidad, profundizamos la siguiente hipótesis: el traslado de los mitayos desde sus pueblos de reducción hasta las minas del macizo charqueño se articulaba a través de caminos y espacios rituales, resignificados en el contexto colonial (Abercrombie, 2006 [1998]). No está de más recordar aquí que la cosmología aymara partía de considerar el tiempo y el espacio como una unidad cíclica, alternando períodos de oposición y conflicto con otros de armonía y conciliación (Harris \& Bouysse-Cassagne 1987). Pasemos ahora a analizar las postas de esos «periplos rituales».

\section{1. Estancia Cantapa (pueblo de Laja, corregimiento de Omasuyos)}

Martti Pärssinen (2005: 237-239) ha sugerido que la estancia agroganadera de Cantapa, situada en términos del pueblo de Laja, habría sido el centro de un sistema de líneas imaginarias (al estilo de los ceques cuzqueños) establecido por el poder incaico; estas línas fungirían de mojones y linderos para los grupos pakaxa (ver figs. 1 y 2)2. El autor refiere a un conflicto que estalló en 1630 entre los caciques de Laja y Guaqui por la posesión de las tierras de Cantapa, destinadas al cultivo de papas y quinua y a la cría de ganado. Aduciendo derechos de posesión desde «tiempo inmemorial», don Baltasar Guamani, cacique principal de Guaqui, don Fernando Quino y don Juan Bautista Vilca Laura, caciques principales de Laja, incursionaban en la memoria colectiva propia y de sus testigos. El «tiempo del Ynga» y la visita toledana fueron hitos que marcaron la memoria y el territorio; ambos rivales remitían a sendos acontecimientos para sustentar sus reclamos. Así, los caciques se acusaban mutuamente de usurpar la estancia, explotar sus recursos y pretender tener jurisdicción sobre sus pastores y demás pobladores.

Roberto Choque Canqui (1993: 20, 56-57, 64-65) interpretó el conflicto en torno a la estancia Cantapa como un mero enfrentamiento económico por tierras y su posterior apropiación por parte de españoles. Su análisis se limita al control de una zona de producción agroganadera necesaria para la reproducción de los ayllu de Guaqui y Laja. Sin embargo, a partir de la sugerencia de Pärssinen, es posible ofrecer una interpretación alternativa para el conflicto. De ser ciertas sus sospechas, y si Cantapa fue un mojón establecido por el Inka para delimitar los territorios de las marka pakaxa, cumpliendo funciones ceremoniales, entonces el pleito entre los caciques estaría dando cuenta de una disputa por el control de un espacio de altísimo poder ritual y político. En efecto, los mojones condensaban referencias simbólicas de la memoria colectiva, la ancestralidad, el culto a los

1 Don Gabriel y don Pedro compartieron la capitanía de mita en los turnos de 1660, 1664 y 1668.

2 Archivo y Biblioteca Nacionales de Bolivia (ABNB), Expedientes Coloniales (EC) 1630-2. El Lic. Polo Ondegardo (1990 [1571]: 469) señalaba que el Inka «especialmente en cada pueblo puso la misma orden y dividió por ceques y rayas la comarca». Para los sura de Paria, Mercedes del Río (2005: 84-93) propuso una interpreración similar, según la cual el tambo incaico de Paria fungía de centro articulador de un conjunto de líneas imaginarias que organizaban el espacio simbólico. Cf. asimismo MacCormack, 2001. 


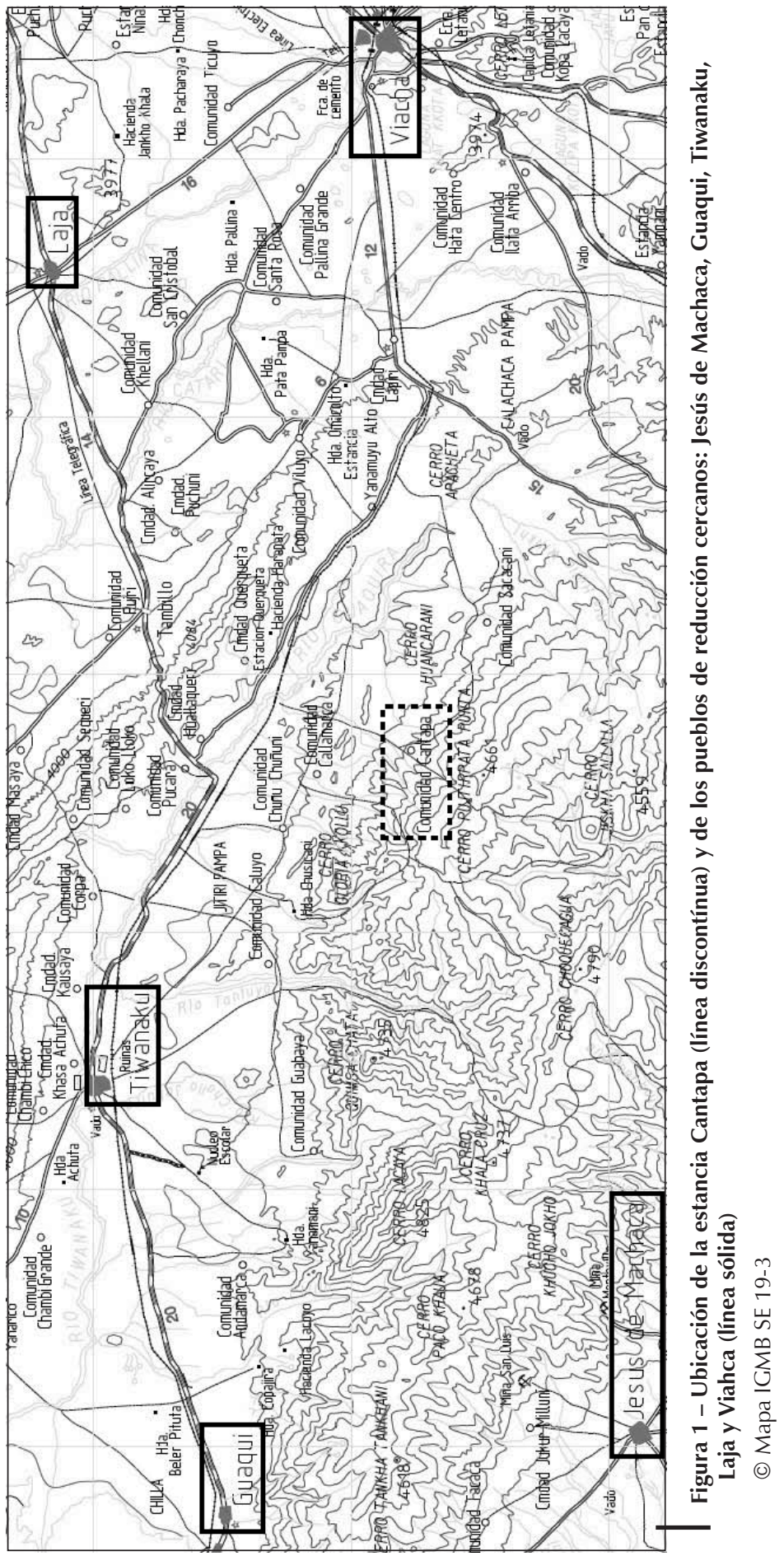




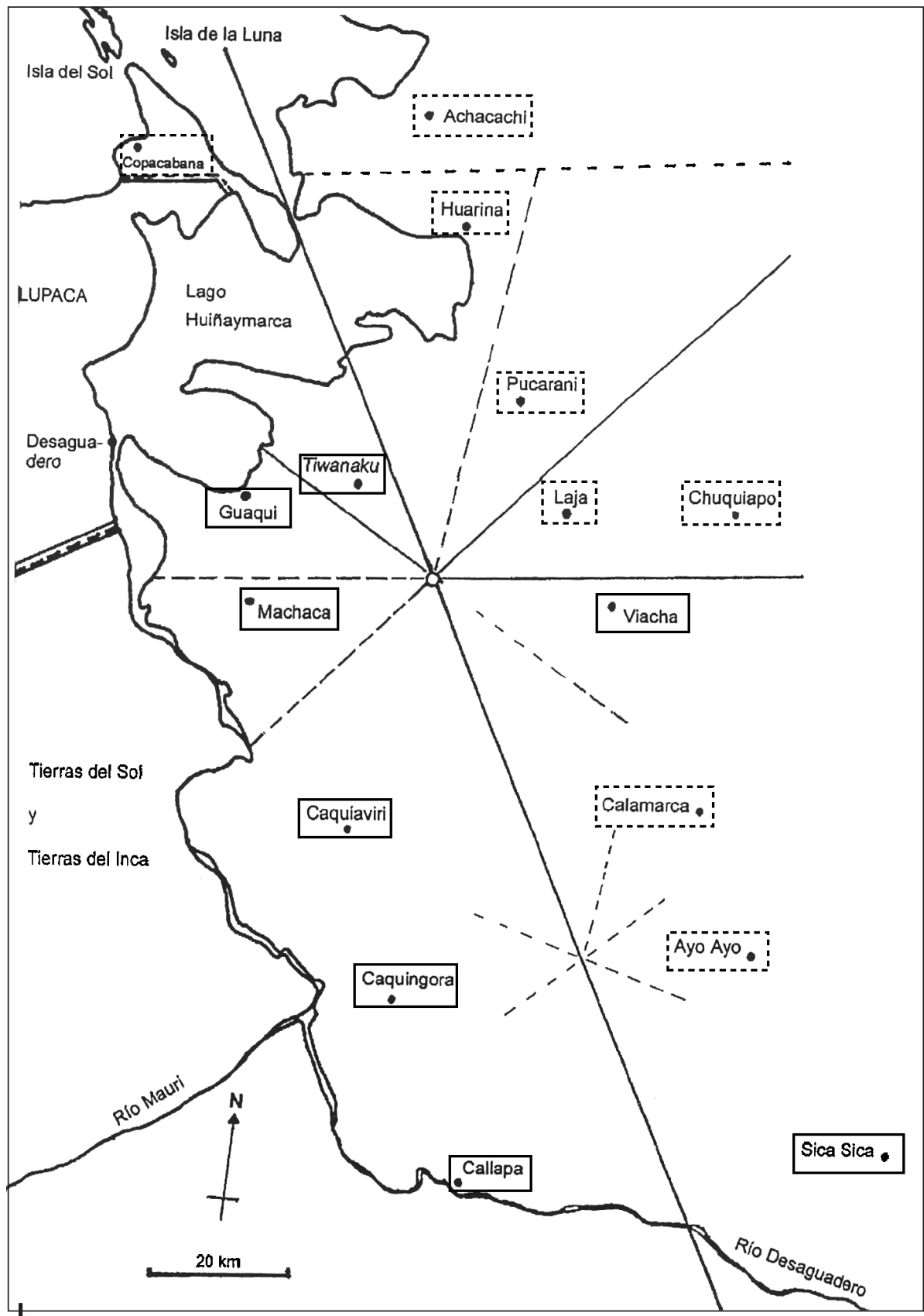

Figura 2 - Unos linderos idealizados de Pacasa vistos desde Cantapa (Pärssinen, 2005: 238)

En línea sólida, las marka correspondientes a la capitanía Pacajes urqu; en línea discontínua, las correspondientes a la capitanía Pacajes uma

(C) Morrone, a partir de Pärssinen, 2005: 238 
cerros y las fronteras entre segmentaciones territoriales (ayllu, parcialidad, marka), reorganizadas a partir del proceso reduccional. En los pleitos por amojonamientos se ponían en juego, pues, aspectos claves de la legitmidad de las autoridades nativas (Del Río, 2005: 84-93; Bouysse-Cassagne \& Chacama, 2012).

Del pleito de 1630 se deriva que una de las variables en disputa fue la propia ubicación de la estancia. En el expediente constan algunas declaraciones que presentan información disímil. La mayoría de los testimonios ubica a la estancia a 5 leguas de Guaqui, entre 1,5 y 3 leguas de Tiwanaku y entre 2 y 4 leguas de Laja (ver cuadro 1). A partir de la medición cartográfica pudimos corroborar que fue el capitán Gonzalo Mexia de Córdoba, corregidor de Pacajes, quien se acercó más a las distancias «reales». El resto de los testigos fueron autoridades étnicas que refirieron distancias aproximadas, lo cual denota la percepción del espacio diferencial con respecto al funcionario español (y con respecto a la concepción occidental del espacio, lineal y cartográfica). Destaquemos las cifras aportadas por los caciques involucrados. Don Baltasar Guamani, cacique de Guaqui, afimaba que la estancia estaba a solo tres leguas de su pueblo, mientras que don Fernando Quino, cacique de Laja, la ubicaba a siete leguas de Guaqui y a menos de dos de Laja. En sus testimonios, las discrepancias entre las distancias señaladas y las «reales» tuvieron, según creemos, una clara motivación política: remarcar la cercanía de Cantapa al propio pueblo y su lejanía respecto del pueblo «rival».

Cuadro 1 - Ubicación de la estancia Cantapa según los testigos

\begin{tabular}{|c|c|c|c|c|}
\hline Testigos & Guaqui & Tiwanaku & Laja & Folio \\
\hline Don Baltasar Guamani, CP Guaqui & 3 & & & $5 r$ \\
\hline $\begin{array}{l}\text { Juan del Campo, protector de natu- } \\
\text { rales, en nombre de los indios de } \\
\text { Guaqui }\end{array}$ & 5 & 2 & 3 & $17 v-18 v$ \\
\hline $\begin{array}{l}\text { Don Alonso Yqui Carala, CP } \\
\text { Tiwanaku }\end{array}$ & & 1,5 & Casi 3 & $19 v$ \\
\hline $\begin{array}{l}\text { Don Martín Nuno Cusi, CP Machaca } \\
\text { la Chica }\end{array}$ & & $\pm 2,5$ & 4 & $21 v$ \\
\hline $\begin{array}{l}\text { Don Diego Caquire, P Ayo Ayo } \\
\text { hurinsaya }\end{array}$ & 5 & $\pm 1,5$ & 3,5 & $22 v$ \\
\hline Don Francisco Cato, P Viacha & 5 & 2,5 & 3 & $23 v$ \\
\hline $\begin{array}{l}\text { Cap. Gonzalo Mexia de Figueroa, } \\
\text { corregidor de Pacajes }\end{array}$ & 5 & 3 & +4 & $24 v$ \\
\hline Don Fernando Quino, CP Laja & 7 & & -2 & $30 v$ \\
\hline $\begin{array}{r}\text { Medición cartográfica (1 legua = } \\
5,57 \mathrm{~km})\end{array}$ & $\begin{array}{c}5,38 \\
(30 \mathrm{~km})\end{array}$ & $\begin{array}{c}3,14 \\
(17,5 \mathrm{~km})\end{array}$ & $\begin{array}{c}4,03 \\
(22,5 \mathrm{~km})\end{array}$ & \\
\hline
\end{tabular}


¿Cómo se resignificó la estancia Cantapa en el contexto colonial? Don Baltasar Guamani afirmó en su declaración que «alli se van juntando cada año los que an de yr a la mita de Potosi y los que buelven de la dicha mita». Uno de sus testigos, Estaban Guerrero, regidor y fiel ejecutor del cabildo, ratificó esta aseveración, ya que «ha visto que los caciques de el dicho pueblo de Guaqui an ydo e ymbiado para las mitas de Potosi por yndios a las dichas tierras y estançia de Cantapa»3. Según el padre Ludovico Bertonio (1984 [1612]: II, 36), la voz «cantata» significa «poner laço a los paxaros, o vicuñas», mientras que «canta» sería «el laço». Esto refuerza el sentido que queremos enfatizar: la estancia Cantapa sería entonces un punto de reunión para los mitayos antes de partir hacia Potosí. El mojón incaico devino nodo articulador de la mita potosina.

Siguiendo las hipótesis de Pärssinen (2005: 239), debería existir otro punto nodal, de similares características, emplazado más hacia el sur, entre Caquingora y Ayo Ayo (ver fig. 2), aunque el autor reconoce que no posee evidencia para sustentar su sospecha. Creemos haber encontrado ese segundo «punto de partida».

\section{2. Asiento de San Diego de Alcalá de Topohoco (pueblo de Caquingora, corregimiento de Pacajes)}

Tenemos señalado que la sistematización toledana de la mita minera retomó parcialmente la territorialidad y la organización política prehispánica. En este sentido, para la región de estudio, el virrey Toledo habilitó dos capitanías: la primera, Pacajes urqu, jerárquicamente superior, incluía los repartimientos de Callapa, Caquingora, Caquiaviri, Machaca la Chica, Machaca la Grande, Guaqui, Tiwanaku, Viacha, Sica Sica y Caracollo; mientras que la segunda, Pacajes uma, jerárquicamente inferior, englobaba los repartimientos de Achacachi, Guarina Pucarani, Laja, Chuquiabo, Copacabana, Calamarca y Ayo Ayo (ver fig. 2) (BouysseCassagne, 1978) ${ }^{4}$. Sabemos que los mitayos de Pacajes urqu se concentraban para marchar a Potosí en el asiento de San Diego de Alcalá de Topohoco, un paraje situado en la jurisdicción del pueblo de Caquingora. Si tenemos en cuenta que Cantapa era el sitio donde se nucleaban los mitayos de la capitanía de Pacajes uma, entonces el asiento de Topohoco bien podría haber sido ese segundo centro nodal que propuso Pärssinen. Por un documento del siglo XVIII sabemos que en noviembre de 1596

3 ABNB EC 1630-2, ff. 6r y 72r-75r. Guerrero vivía desde 1602 en Viacha, Tiwanaku y Machaca la Chica, y había sido corregidor de Pacajes, lo cual le otorgaba un notable conocimiento del terreno y alta credibilidad a su testimonio.

4 Según la autora, los grupos altiplánicos construyeron su identidad en torno a las categorías urqu/ uma. A partir de una relación opuesta aunque complementaria, los urqu (habitantes de las alturas) habrían adoptado, en su carácter de valientes guerreros, una mirada despectiva respecto de los uma (habitantes del medio acuático), quienes pertenecían a una humanidad inferior y anterior, como resabio de épocas pasadas. 
El Virrey Don Luis de Velasco ordenó que los indios de cada distrito se congregasen en la parte más cómoda de la provincia para que de allí salieran todos juntos a la mita de Potosí (...) los de Pacaxes en San Diego de Topoco que dista ciento treinta leguas (...) los de Omasuyos en Laxa que dista ochenta y cuatro leguas (Cañete y Domínguez, 1974 [c. 1771]: II, 191 [ff. 190v-191r])5.

Encontramos las primeras referencias al asiento de Topohoco en un pleito trabado en agosto de 1633 entre don Gabriel Fernández Guarachi, cacique principal de Jesús de Machaca y capitán de mita, y el corregidor de La Paz, don Antonio Mogollón de Rivera. El capitán de mita estaba urgido por efectuar la reducción de varios mitayos faltantes, y reveló que el corregidor de La Paz había liberado algunos mitayos prisioneros en la cárcel pública de la ciudad. Fernández Guarachi presentó dos denuncias: una ante el alférez Diego de Olmedo Marquina, teniente de corregidor de Pacajes, y otra ante don Juan Laura y Domingo Curisara, alcaldes ordinarios del pueblo de Caquiaviri. En ambas, la principal preocupación radicó en

que por estar la mita de Topoco de proximo la qual no podra enterarse si la reducion no ba adelante (...) y porque estas cosas no requieren dilacion por estar el despacho de Topoco muy de proximo y sin la reducion no se puede despachar» (ABNB Minas (Min) 123-11, ff. 4v y 6r).

Así, en octubre del mismo año, Omedo Marquina «era ydo a los pueblos de su jurisdiçion a recoxer los yndios de la mita de Potosi para despacharla en el asiento de Topoco».

Entre tanto, el Dr. don Juan de Molina, canónigo de la catedral paceña y comisario del Santo Oficio, había ordenado que Olmedo Marquina saldara una deuda de 500 pesos corrientes que tenía con Alonso Ramírez de Abreu, quien a su vez los adeudaba al Santo Oficio. Sobre Topohoco, último paradero de Olmedo Marquina, el canónigo afirmaba «no estar el dicho asiento mas de seis leguas» del pueblo de Ayo Ayo, a cuyo cura, Lic. Antonio de Arisaga, exhortó para que capturara al evasor alférez (Archivo de la Curia Arzobispal de La Paz (ACALP, Tomo 1, ff. 162r-162v.). El expediente continúa resaltando el rol clave del corregidor de Pacajes, general don Rodrigo de Castro y Bovadilla, y de su teniente Olmedo Marquina en el entero de la mita:

Por quanto aviendo venido Su Merced a esta ciudad de La Paz en prosecuçion de las deligencias que esta haciendo para el despacho del entero de la mita que se a de ynbiar a la villa de Potosi desde el asiento de Topoco que es de cantidad de mil e tresçientos y tantos yndios e dexado en su provinçia para el buen despacho della al alferez Diego de Olmedo su teniente general por ser como es persona deligente y cuidadosa y que sin ella corre detrimento el despacho de la dicha mita por estar Su Merced tanbien ocupado en las propias deligencias las quales son de servicio de Su Magestad y tanto porque sin ella aviendo falta en la dicha mita no abra 
quintos ni paga de su Real Hacienda en la dicha villa de Potosi y estando desta suerte y el tienpo tan breve del dicho despacho porque se a de haçer y concluir en todo este mes de noviembre (ACALP Tomo 1, f. 164r)6.

Estas referencias documentales ubican al asiento de Topohoco a mitad de camino entre Caquingora y Ayo Ayo, en el lugar preciso en que Pärssinen sospechaba debía existir un segundo centro nodal que sirviera de mojón para los pakaxa más meridionales. Y del mismo modo que la estancia Cantapa, Topohoco fue punto de reunión de los mitayos que partían a Potosí.

Hallamos más información sobre el asiento de Topohoco en las respuestas a un interrogatorio que en 1662 realizara don Lorenzo Vázquez de Castilla, cura de San Andrés de Machaca, sobre los llamados «indios marahaques»». Para mediados del siglo XVII asistimos al desarrollo de una «mita de facto» que difería largamente del ideal plasmado en las ordenanzas toledanas. Una de las prácticas vistas por los españoles como «deformaciones» de la mita era la existencia de los «indios marahaques». Para obtener el dinero necesario para costear los tributos, muchos caciques literalmente «vendían», a través de una escritura pública, la fuerza de trabajo de gran cantidad de mitayos quienes, desviados del ciclo «tradicional» de la mita, terminaban trabajando para hacendados y comerciantes en estancias y trajines (Cole, 1985: 36). Así, García Colque, cacique y segunda persona del ayllu Achacana de San Andrés de Machaca respondía

Que sabe por vista de ojos que 6 años a esta parte se usa una cosa en Topoco que jamas se ha usado y es que hay una feria o tienda publica donde se venden los indios en esta forma: que se hace una lista para los indios para que vayan a Potosi a trabajar y van los españoles a sacar los indios para sus maharaques que son indios que han de trabajar un año o dos y estos son pastores de ovejas, vacas, carneros de la tierra y otros ganados y les pagan cada día 2 reales y que coman dellos y si les dan chuno o maiz se los cuentan a 5 pesos ó 4 y han de servir forzosamente 2 años enteros por solos 150 pesos y que estos se dan a los hilacatas de cada ayllo y estos los enteran a los capitanes generales (AGI, Escribanía de Cámara 868A, primera pieza, f. 523r, citado en Cañedo-Argüelles Fábrega, 1993: 120, y en Wachtel, 2001 [1990]: 442, nota 84).

Años más tarde, en 1685 el corregidor de Pacajes don Diego Barraza Enríquez señalaría que el asiento de Topohoco era el «parage donde se despacha la real mita de Potosi» (ABNB EC 1689-35, f. 18r)8. Acudimos nuevamente al padre Bertonio, quien nos ilumina sobre el significado del nombre del asiento, toda una metáfora coincidente con la memoria, el pasado, las obligaciones laborales

6 El énfasis es nuestro.

7 AGI, Escribanía de Cámara 868A, primera pieza, citado en Cañedo-Argüelles Fábrega, 1993: 112122.

8 Sobre los «indios marahaques» y la «feria» de Topohoco, cf. Cañedo-Argüelles Fábrega, 1993: 8688; Wachtel, 2001 [1990]: 442-446; Tandeter, 1992: 78; Choque Canqui, 2003: 113 (nota 88), 139 (nota 40), 182, 185 y 249. 
y el espacio (Bertonio, 1984 [1612]: II, 365)9. La voz aymara tupu remite a una unidad de medida utilizada en «tiempos del Ynga»; en asociación a la voz cama encontramos que camatha y camattatha, tuphuttatha significan «medir con vara, o hanega, açumbre, soga», pero también se asocia a la voz thaqui, que implica «camino, senda, atajo» (Bertonio, 1984 [1612]: II, 35 y 345). El campo semántico se arma en torno a la idea de «medir el camino real» y a las unidades de medida utilizadas por el Tawantinsuyu. El cronista Garcilaso señalaba, por su parte, que un tupu equivalía a una fanega y media de tierra (poco más de una hectárea), y que servía para sustentar a una pareja durante un año, mientras que cada hijo varón que se sumaba a la unidad doméstica representaba un tupu adicional y cada hija mujer, medio tupu. Este lote familiar se reajustaba, según el cronista, cuando la nueva generación formaba nuevas unidades domésticas (Murra, 1999 [1978]: 63). ¿Es posible medir los caminos en términos incaicos? Los «sistemas» incaicos de «medición» del tiempo y las distancias estaban ritualmente asociados a conceptualizaciones espaciales y prácticas políticas (Sanhueza Tohá, 2004). En el pleito por la estancia Cantapa, don Martín Calle, anciano principal del ayllu Achaca de Tiwanaku hurinsaya, afirmó que esas tierras «son como una legua de ynga poco mas o menos», mientras que don Baltasar Guamani, cacique principal de Guaqui, sostenía que

desde el tiempo del Ynga emos tenido y poseydo una estancia llamada Cantapa que esta poco mas de tres leguas deste pueblo (...) en contorno quel dicho Ynga nos dio y señalo para nosotros y nuestros herederos (ABNB EC 1630-2, ff. 5r y 90r).

Si bien resulta aventurado buscar equivalencias entre la «legua del ynga» y el sistema de medición español (que tampoco era completamente fijo), solo a modo de ejercicio aplicamos la equivalencia 1 legua $=5,57 \mathrm{~km}$ al contorno de la estancia Cantapa, que mediría entonces casi $17 \mathrm{~km}$. ¿Podemos deducir, entonces, que la una «legua de ynga» equivalía a $17 \mathrm{~km}$ ? ¿Sería una «legua de ynga» la medida que apelaba al camino o a los «pasos» del Inka sobre los territorios conquistados? ¿Estamos en presencia de las huellas del Inka?

El nombre Topohoco tiene un segundo componente, que se asocia a la voz quechua ukhu; según Diego González Holguín, ukhu refiere a «lo de dentro», «en lo interior, y en lo hondo» (González Holguín, 2007 [1608]: 238. Cf. Randall, 1993: 107). Siempre en el plano de los simbolismos y las hipótesis, ipodemos pensar en el asiento de Topohoco como una posta en el camino y, a la vez, una puerta simbólica de entrada a un viaje que tendrá como destino final las minas del macizo central charqueño? Sabemos que las afloraciones rocosas, los aleros y la cuevas eran percibidas (incluso lo son hasta nuestros días) como espacios rituales permeables para la intermediación, como puertas (punku) hacia distintos planos simbólicos de la realidad (Cruz, 2006) ¿Se trataría de una vía de acceso al mundo

9 «Tupu, vel Cama: La medida. Tupu: Legua del camino a la medida del Inga.Tupo, vel Thaqui: Camino real». 
de los ancestros, un «mundo interior», introspectivo y subterráneo a la vez? ¿Entrar en las minas, entonces, sería regresar a un pasado, en términos cíclicos de pacha? ¿Provocaría el consumo de alcohol y otras sustancias psicotrópicas ciertos estados alterados de conciencia que habilitaran la recreación de la memoria colectiva ancestral y la comunicación de los mitayos con sus antepasados a lo largo de las distintas «estaciones» del camino?

El panorama presentado hasta aquí con respecto al asiento de Topohoco se complejiza aún más si agregamos un comentario acerca del nombre cristiano del lugar. Sabemos que el franciscano San Diego de Alcalá, OFM (1400-1463, canonizado en 1588) había sido portero del convento de Arrecife en Lanzarote y guardián del convento de Fuenteventura (Canarias) entre 1441 y 1449; luego, en 1456 fue asimismo portero del convento de Santa María de Jesús de Alcalá de Henares10. No sería casual que el poder eclesiástico colonial (iacaso los franciscanos de Caquiaviri?) haya «bautizado» al asiento de Topohoco (puerta simbólica de un viaje sagrado) con el nombre de un santo que había ejercido, justamente, los oficios de portero y guardián. De hecho, San Diego había nacido en San Nicolás del Puerto, un frío y montañoso pueblo del noroeste andaluz, que registra explotación de minas de plata desde el período de dominio árabe. ¿Es que estamos ante la introducción de un culto minero andaluz en el altiplano aymara? ¿Sería San Diego de Alcalá el portero y guardián de Topohoco? (BouysseCassagne, 2004; Querejazu Escobari, 2011).

La evidencia documental del siglo XVII presentada hasta aquí es coherente y permite sostener la hipótesis de la existencia de dos puntos simbólicamente centrales, en clave de dualismo equilibrado, que pudieron haber sido mojones establecidos por el Inka en su conquista de la jefatura pakaxa y luego resignificados por el poder colonial en función de la organización de la mita minera, acaso replicando las diferencias, jerarquías y precedencias. María Rostworowski (2003) sostiene que los destinos de varios circuitos de peregrinación prehispánicos eran parajes escasamente habitados, en función de acuerdos entre líderes de segmentos políticos eventualmente enemigos y como instancia del intercambio de bienes. No resultaría fortuito que el gobierno colonial seleccionara estratégicamente dos nodos centrales en la geografía local para llevar adelante el reclutamiento y concentración de la mano de obra mitaya antes de partir hacia Potosí, nodos que quizás hubieran cumplido un rol similar para la mit'a al Tawantinsuyu. No disponemos al presente de información arqueológica para complementar el registro documental, pero intuimos que el trabajo multidisciplinario aportaría material relevante para revisar nuestro modelo interpretativo, que plasmamos en la figura 3. 


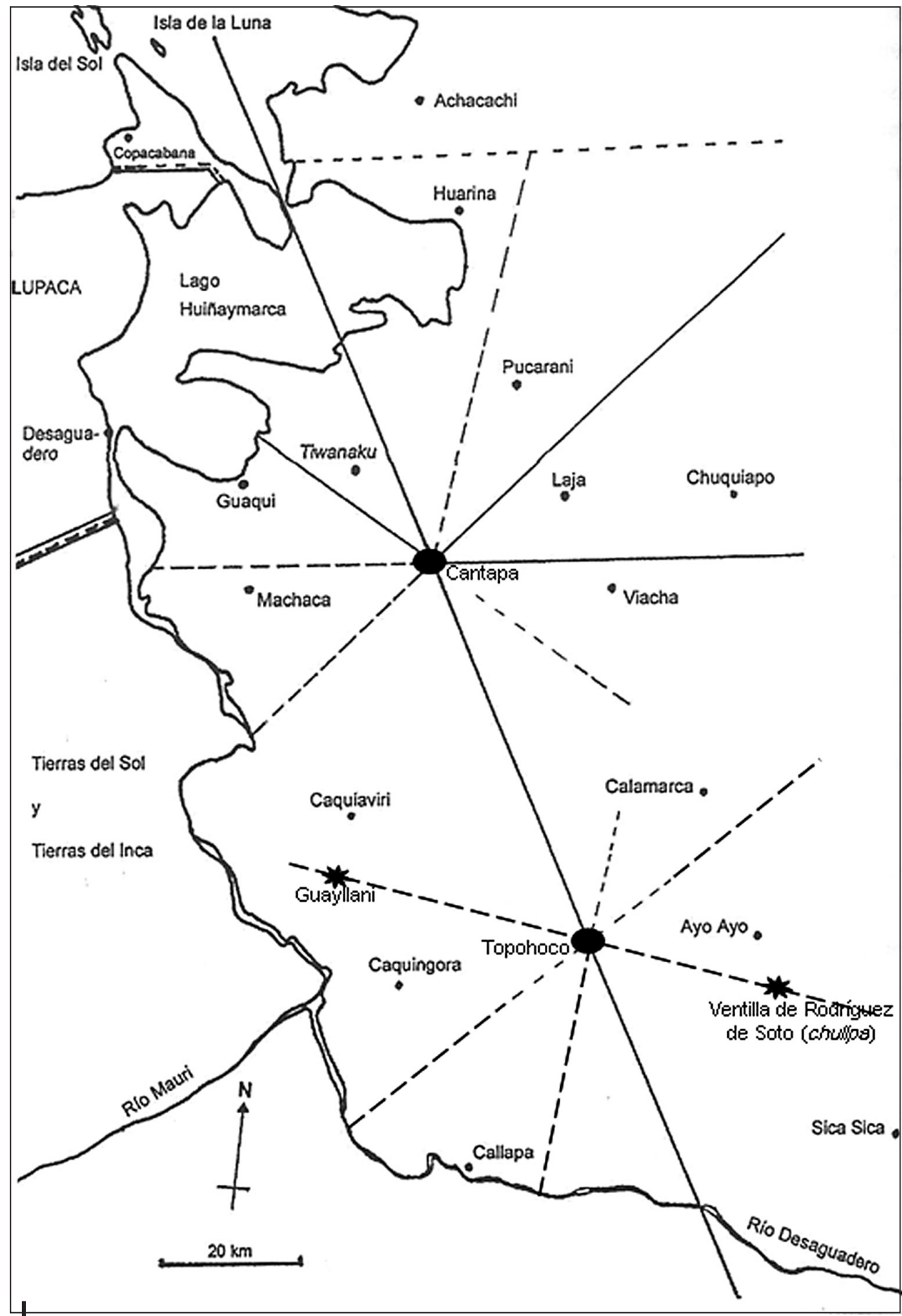

Figura 3 - Cantapa y Topohoco como espacios simbólicos y nodos centrales: de mojones incaicos a focos de concentración de la mita (modelo de interpretación)

(C) Morrone, a partir de Pärssinen, 2005: 238 


\section{3. Estancia Guayllani (apacheta) y venta de Rodríguez de Soto (chullpa)}

Pero más aún: encontramos otros mojones en esta geografía ritual. En el contexto de la revisita al pueblo de Laja, realizada en 1625, los caciques tuvieron que dar cuenta del paradero de Pedro Suri, tributario del ayllu Copaquira de la parcialidad hurinsaya:

Pedro Suri tributario casado de hedad de treynta y quatro años dizen sus caciques murio yendo a la mita de Potosi en el camino en la apacheta de Guayllani de que dara ynformacion no saben el nombre de la muger porque era forastera de la provincia de los Canas no tienen hijos ni haçienda y sus casas caidas (Archivo General de la Nación (AGN, Sala XIII, 17-2-3. Revisita al pueblo de Laja, f. 146v) ${ }^{11}$.

La referencia a una apacheta en el camino a Potosí llama nuestra atención. ¿Sería esta apacheta una parada ritual? La visita general de 1683 registra una estancia Guayllani en términos del pueblo de Caquingora, dependiente del ayllu Sirpa, proveedor de autoridades del pueblo (AGN XIII, 18-1-2. Visita al pueblo de Caquingora). Asimismo, en el pleito que don Felipe Alejo Sirpa Tico, cacique principal de Canquingora, trabó entre 1684 y 1689 con Diego Ortuño de Amoraga, a la sazón propietario de las tierras de Guayllani, consta que las mismas se destinaban al cultivo de papa y al pastoreo de ganado, y que «se alindan con las tierras de Caquiavire» en «jurisdicion del pueblo de Caquingora como cinco leguas del» (ABNB EC 1689-35, ff. 2r y 57v). Estas referencias nos permitieron ubicar la estancia aproximadamente a $28 \mathrm{~km}$ del pueblo de Caquingora, cerca de la actual localidad de Sirpa, de camino a Caquiaviri. En nuestro modelo de interpretación, asociamos la apacheta de Guayllani que figura en la revisita de 1625 con la estancia homónima, que quedaría emplazada sobre la línea imaginaria que, partiendo de Topohoco, corre entre Caquingora y Caquiaviri (ver fig. 3).

Asimismo, sabemos que entre octubre de 1594 y febrero de 1595, Juan Rodríguez de Soto, vecino de La Paz y alcalde en 1593, adquirió por 80 pesos ensayados (en el contexto de las composiciones de tierras iniciadas en 1591) un solar «entre los pueblos de Hayo Hayo y Sicasica junto a unas sepolturas (...) y que tiene por linderos el camyno real por delante y por las espaldas un rio y a un lado unas sepolturas». Allí Rodríguez de Soto planeaba «hazer y edificar una venta para el albergue y buen aviamiento de los pasageros sin que ninguna persona se lo estorbe»12. Por su parte, fray Alonso Ramos Gavilán (1976 [1621]: I, cap. XIX) recordaba que en Sica Sica, hacia 1598, un barretero halló por casualidad a una

11 El énfasis es nuestro. Según Bertonio (1984 [1612]: II, 23), el término apachita significa «Monton de piedras, que por supersticion van haziendo los caminantes, y los adoran».

12 Archivo de La Paz (ALP) Expedientes Coloniales (EC), Caja 1 Expediente 32. Desconocemos si se trata de Juan Rodríguez de Soto, encomendero de Sica Sica nombrado por Pedro de La Gasca, quien gozaba de la merced por lo menos hasta 1583, o de algún familiar (acaso su hijo). Cf. Cook, 1975: 62-63; y Hampe Martínez, 1979: 87. 
niña de diez años dentro de una chullpa, tapiada por los caciques locales como ofrenda «a sus vanos dioses» (MacCormack, 1991: 419).

El registro arqueológico evidencia una gran concentración de torres funerarias rectangulares (chullpa) que databan de mediados del siglo XIII a pocos kilómetros al sudoeste de Sica Sica (Kesseli \& Pärssinen, 2005: 391-393). La construcción de chullpa en el altiplano aymara estuvo asociada a un conjunto de transformaciones climáticas, demográficas y sociopolíticas que se desataron en la cuenca del lago Titicaca a partir de la segunda mitad del siglo XIII. Del mismo modo que los cerros nevados, representación topográfica de los ancestros comunes, petrificados y divinizados, las chullpa también devinieron en marcadores territoriales, una forma de impregnar las relaciones sociales en el espacio, incluso en tiempos coloniales ${ }^{13}$. Este paisaje sacralizado deviene en un soporte de la memoria colectiva, que se articula en torno al reconocimiento de huellas específicas en el espacio. Como garantes de esa memoria colectiva, la gente del común esperaría de sus líderes étnicos no solo el reconocimiento de los marcadores topográficos, sino también la garantía de la continuidad de los cultos a los ancestros, que permanecen en la esfera privada, doméstica y «mágica» (Farris, 1992 [1984]).

Teniendo en cuenta estas consideraciones, las «sepolturas» que servían de linderos para la «ventilla de Rodríguez de Soto» bien podrían haber sido parte de este complejo chullpario, que a la vez podría delimitar las áreas de influencia y control entre Ayo Ayo y Sica Sica. ¿Acaso las chullpa de la ventilla también formaran parte del complejo radial que partía de Topohoco?

Cobra mayor sentido, entonces, pensar la apacheta-estancia de Guayllani y la chullpa-ventilla de Rodríguez de Soto como hitos en el camino entre los sitios de reclutamiento de los mitayos y el asiento de Topohoco. Asimismo, tanto las apacheta como las chullpa remiten directamente al mundo de los antepasados, en tanto funcionan en la cosmovisión aymara como metonimia de los ancestros litomorfizados (Duviols, 1976a). Se trata, entonces, de pensar estos mojones como postas en la ruta, cuyas paradas rituales cubrían el viaje temido, desgarrador y tal vez sin retorno, hacia Potosí.

\section{LAS HIPÓTESIS PUESTAS EN JUEGO}

Varios son interrogantes que surgen a partir de nuestro análisis. ¿Fueron Cantapa y Topohoco efectivamente espacios rituales? ¿Qué ceremonias se realizarían allí? ¿Se trataba de espacios sagrados preincaicos, o fueron sacralizados por el Tawantinsuyu? ¿Cómo se transmitieron los saberes al punto de que los mismos espacios fueran resignificados en el contexto de la mita potosina? ¿Qué juegos de saber-poder se operaron? A la hora de describir las prestaciones laborales

13 Cf. Sendón (2010), quien plantea una asociación estrecha entre la construcción de torres funerarias y las pautas de reproducción de sociedades pastoriles, en términos de marcadores territoriales y espacios de culto a los antepasados. Cf. asimismo Gil García, 2001 y Bouysse-Cassagne \& Chacama R., 2012. 
rotativas al Tawantinsuyu, los cronistas reprodujeron la ficcionalización y el enmascaramiento de la explotación (incaica primero, colonial después). El propio Ondegardo (1990 [1571]: 50) explicaba

que todo el pueblo como se hallaban presentes salían a ello, sin salir viejo ni enfermo, sino la gente de trabajo vestidos cada uno con lo mejor que tenían y cantando cantares apropiados a la materia (Murra, 1999 [1975]: 149).

No podemos más que instalar filtros a las crónicas y tomar distancia de las mismas para evitar caer en la tentación de interpretarlas literalmente. En tanto sistema de dominación, el Tawantinsuyu elaboró un discurso legitimador, que hacía pasar por reciprocitarias prácticas eminentemente coactivas; y de modo menos «simbólico», el poder colonial resignificó la mit'a incaica para ajustarla a sus propios intereses.

Nuestro análisis corre por otros carriles. Siempre tomando las precauciones necesarias, y volviendo al altiplano, sugerimos que Cantapa y Topohoco constituyeron paisajes imperiales. A diferencia de los centros administrativos de mayores dimensiones y complejidad (como Hatunqolla o Huánuco Pampa), eran parte de un patrón espacial radial organizado desde espacios relativamente alejados de las marka pakaxa, que prefiguraban la imposición de un nuevo poder a través de una geografía sagrada (Acuto, 1999). Es probable que, una vez vencidos por el poder cuzqueño, los líderes pakaxa debieran aceptar la reorganización de su territorio. Tras la conquista española y la implementación de las reformas toledanas, los antiguos (o no tan antiguos) paisajes imperiales fueron resignificados en el contexto de la mita minera.

Ahora bien, nuestro modelo de interpretación presenta incongruencias. Verificamos un desfasaje entre los repartimientos que quedarían bajo la órbita de ambos nodos radiales, por un lado, y los repartimientos correspondientes a cada capitanía de mita, por el otro. Algunos repartimientos integrados en la capitanía Pacajes urqu (Guaqui, Tiwanaku, Viacha, Machaca la Grande y Machaca la Chica) estaban emplazados en la órbita de la estancia Cantapa, donde se reunían los mitayos de la capitanía Pacajes uma, mientras que el repartimiento de Ayo Ayo, correspondiente a esta capitanía, se hallaba bajo la órbita del asiento de Topohoco (lugar de encuentro de los mitayos de Pacajes urqu). Asimismo, los repartimientos de Caquiaviri y Calamarca se hallaban en un espacio intermedio entre ambos nodos, aunque pertenecían a distintas capitanías de mita. No podemos ofrecer al presente una explicación cabal para estos desfasajes, pero probablemente se trate de reconfiguraciones territoriales operadas por los poderes incaico y español en el espacio pakaxa.

¿Cuál era la situación en el otro extremo del camino, es decir, al llegar a Potosí? Durante el gobierno del virrey Velasco (1596-1604), el jesuita Alfonso Messia describía críticamente los padecimientos de los mitayos:

Reciben daño en sus almas, que como se ausentan los indios tres y cuatro meses y á veces mas de cinco, y estas ausencias son ordinarias, se les olvida lo que saben de nuestra fé, no oyen misa en todo este tiempo, en los caminos cometen graves pecados, que no harian si estuvieran en sus 
casas y con sus mujeres, y ellas no menores con la ausencia de sus maridos (Torres de Mendoza, 1865: VI, 131-132)14.

El camino de la mita a Potosí constituía una instancia propicia para «cometer graves pecados», según el jesuita. En nuestro ejercicio de interpretación, vislumbramos a los mitayos del Collao mochando y alabando a sus ancestros entre bailes y libaciones. Sin embargo, Messia guardaba sus reservas con respecto al libre ejercicio de esas prácticas:

Hay un descuido grande en permitir las borracheras á los indios, públicas en las calles y plazas, y como cosa en que no creo que se repara, pues no se remedia. En Potosí, estando yo un día de fuera por las calles forzosas que pasan para ir al Colegio, antes de anochecer, vi tres borracheras públicas, dos en dos corrales y otra en la misma calle, con sus danzas y atambor y mates de chicha en las manos, que cuando estaban los indios en sus idolatrias, no podian ocuparse en este ejercicio con más seguridad y devocion. Mande V. E. á todos los alguaciles que les derramen la chicha, yá cualquier alguacil que los viere y á los caciques que lo permitieren, dén seis dias de cárcel por la primera vez y por la segunda doce, y castígueseles de esta manera, de suerte que tenga remedio vicio tan pernicioso y tan nocivo para sus almas y cuerpos (Torres de Mendoza, 1865: VI, 163).

Messia denunciaba el carácter «público, notorio y escandaloso» de estas prácticas, e instaba a las autoridades locales a castigar a los caciques que no pudieran controlar la situación, incumpliendo lo que se esperaba de ellos en tanto «buenos caciques coloniales». En 1609, el Lic. Alonso Maldonado de Torres, presidente de la Audiencia de Charcas, informaba en carta al Rey sobre el comportamiento de los mitayos y el diagnóstico de lo que consideraba necesario para enmendarlo, en la misma línea del jesuita Messia:

lo que ganan de jornal los que sirben en las minas y trajines lo consumen y beben el dia que se les da sin mirar adelante y asi es gente con quien se ha de proçeder con algun mas apremio que la que usa de razon y puliçia y no dexarlo a su dispusiçion y voluntad que sera huyr del trabajo y desampararlo todo y bolberse a sus antiguos ritos y ydolatrias ${ }^{15}$.

Corroboramos así la clásica asociación entre ocio, consumo excesivo de alcohol y cultos sindicados como «idolátricos». Los caciques debían mantener el control de su gente pero, al mismo tiempo, si optaban por la represión de ciertas prácticas, su legitimidad interna podría ponerse en juego (Saignes, 1987).

De los espacios de residencia a los pueblos de reducción; de allí, al asiento de Topohoco y la estancia Cantapa, pasando por apachetas y chullpas; luego, el camino llegaba a los cerros de Potosí y Porco, e incluso al «pueblo viejo» de Pacaxa, asentamiento de antiguos colonos transplantados por el Estado incaico

\footnotetext{
14 El énfasis es nuestro.

15 Colección «Gaspar García Viñas» de Copias de Documentos del AGl, Biblioteca Nacional, Buenos Aires, Tomo 189, Documento 4025. Potosí, 19 de febrero de 1609.
} 
con fines productivos, emplazado frente a un cerro que los españoles llamaron, no casualmente, «Poder de Dios» (ver fig. 4) (Platt et al., 2006; Morrone, 2010a). De este modo, sugerimos un «viaje ritual», articulado en la memoria colectiva y en el territorio.

\section{CONSIDERACIONES FINALES}

Este artículo constituye uno de nuestros primeros intentos por indagar las bases simbólicas de la legitimidad interna de los líderes étnicos, a partir de las variables de religiosidad, territorialidad y memoria. Procuramos dar cuenta del rol de los caciques como capitanes de mita (asociando su accionar con el mantenimiento de ciertos cultos prehispánicos), como así también de los discursos construidos desde el segmento dominante de la sociedad colonial. Si bien el «orden toledano» había establecido un canon de lo que significaba ser un «buen cacique», las hipótesis trabajadas aquí nos llevan más allá de las prescripciones del poder colonial.

Es clave para nuestra argumentación entender que la religiosidad indígena remite de lleno a la memoria colectiva, y que esta encuentra su anclaje en un espacio socialmente construido. Las sociedades andinas en general y los grupos altiplánicos en particular manejaron (y manejan) una concepción ritual del espacio. En esta línea, la territorialidad no resulta un molde abstracto que clasifica y separa poblaciones y espacios, sino un dispositivo que promueve su cohesión (Sack, 1986: 62). Recordar/recortar espacios rituales, emprender caminos de la memoria y auspiciar instancias de sociabilidad fueron las prácticas que vislumbramos en los caciques coloniales. Tales operaciones no se propusieron reflejar el pasado y negar el paso del tiempo; respondieron, más bien, a intereses concretos emanados de coyunturas en las que las posiciones y los roles de los líderes étnicos se vieron puestas en juego. La sistematización toledana de un orden colonial y la implementación de la mita potosina fueron hitos en los que fue conveniente reconfigurar selectivamente la memoria colectiva a partir de objetos, paisajes y símbolos. En efecto, la memoria transforma el pasado conocido en lo que debería haber sido, elimina algunas escenas no deseadas, subraya otras más significativas y las reordena en una nueva construcción discursiva (Lowenthal, 1975: 28). El auspicio de estas prácticas rituales por parte de las autoridades étnicas podría pensarse como una instancia para la reactivación de los vínculos entre el órden cosmológico y el orden social, en un camino que reconstruye la memoria colectiva, al tiempo que refuerza las solidaridades internas y las legitimidades de las autoridades políticas (Duviols, 1976b).

Quisiéramos remarcar que, a pesar de considerar que la pervivencia de ciertas prácticas de religiosidad prehispánicas fueron claves para el sostenimiento de la legitimidad de los caciques coloniales, no concebimos a los grupos surandinos como impermeables frente al cambio. La posición mediadora de los caciques coloniales fue contingente a las transformaciones acaecidas tanto en el segmento dominante como en los colectivos étnicos que lideraban, y hasta cierto punto su posición y su rol sociopolíticos fueron emergentes de esas transformaciones. Del mismo modo, en cuestiones de religiosidad interpelamos a estas figuras 


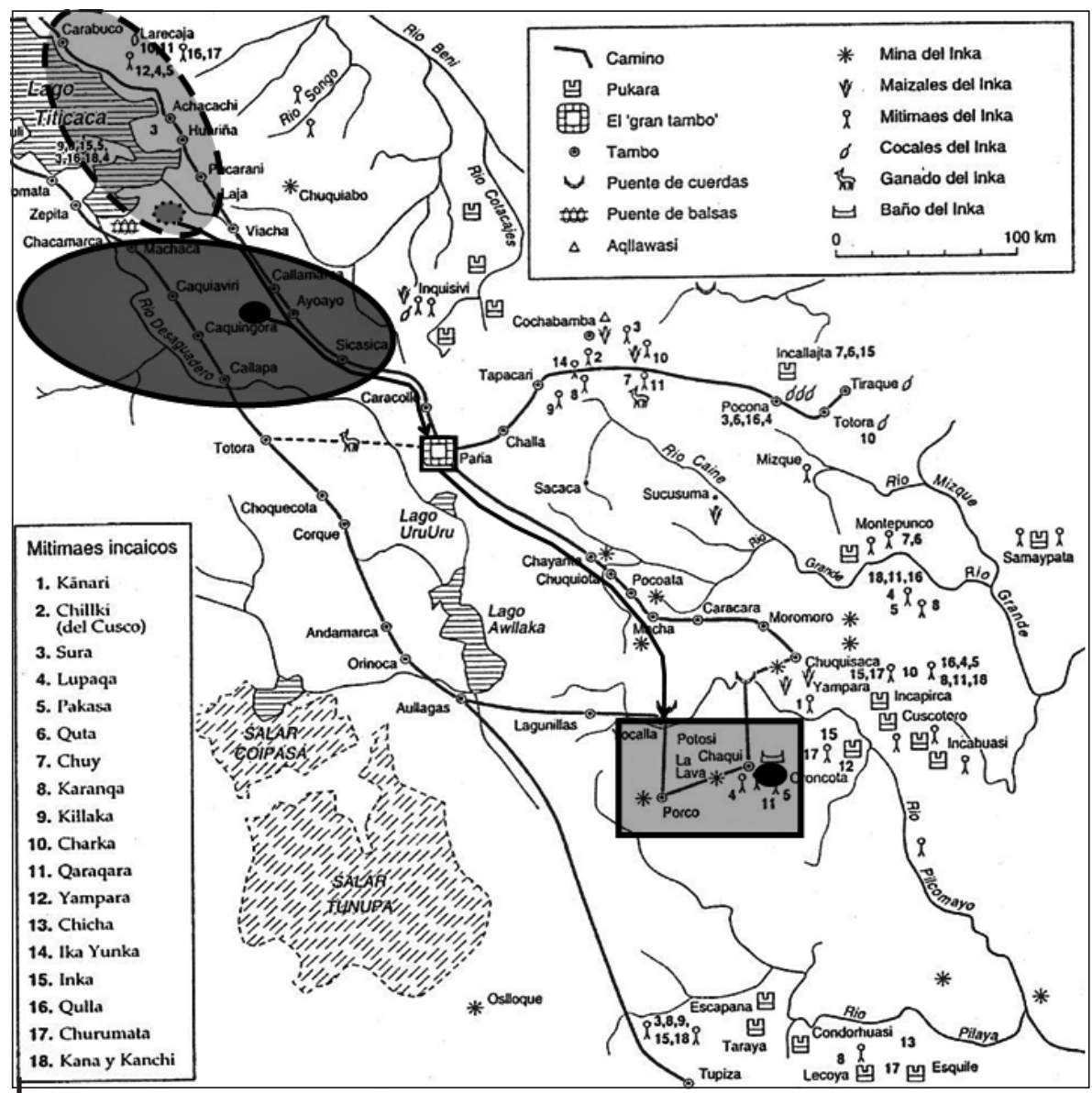

Figura 4 - El camino a Potosí. Capitanía Pacajes uma y la estancia Cantapa (elipse de línea discontínua). Capitanía Pacajes urqu y el asiento de Topohoco (elipse de línea sólida). Minas de Potosí y Porco, cerro del Poder de Dios y pueblo viejo de Pakaxa, mitimaes (rectángulo)

(C) Morrone, a partir de Platt, Bouysse-Cassagne \& Harris, 2006: 82

intermediarias a caballo entre dos sistemas de creencias (el indígena y el cristiano), que a su vez tampoco fueron monolíticos, sino efectos de intersecciones entre pautas, cultos y creencias de diversos orígenes y profundidades temporales.

El avance del proceso de cristianización de la población indígena es indudable. En un primer momento, el mismo intentó imponerse de manera feroz, destruyendo templos, santuarios, adoratorios, objetos e imágenes asociadas tanto al culto imperial incaico como a los cultos locales. Si bien es posible proponer un análisis de las prácticas articuladas para mantener y reproducir la memoria colectiva, también podemos pensar en prácticas contrarias, destinadas a destruirla. Pero andadas varias décadas de dominio colonial, la cristianización cristalizó en un modo de ejercer la religiosidad específica del espacio andino (o altiplánico), 
que podríamos llamar «aymarización del cristianismo» o «cristianismo andino colonial» (Farris, 1992 [1984]; Stern, 1986 [1982]). Esta manera específica, local y hasta «creativa» de ejercer el cristianismo permitió a los líderes étnicos, tal como venimos sosteniendo, redefinir sus criterios de legitimidad, y a la «gente del común», reconfigurar los sistemas de creencias una vez «superado» el traumatismo de la Conquista. En tanto intermediarios culturales, los caciques pudieron habitar esa «zona de contacto» entre varios sistemas de creencias, «aymarizando» el cristianismo en términos de religión local (Christian, 1991; Taylor, 2000). Por nuestra parte, propusimos analizar la mita potosina bajo el prisma de la religiosidad, sin dejar de lado el carácter explotativo de esta institución colonial. Se trata de una hipótsis de trabajo, un modelo de interpretación. Futuras campañas de relevamiento documental y la incorporación de trabajos arqueológicos aún por hacerse validarán o refutarán las ideas aquí barajadas. Entre tanto, seguimos reflexionado sobre el proceso de construcción del liderazgo étnico a partir de la religiosodad, la memoria colectiva y los espacios rituales.

\section{Agradecimientos}

Este artículo recupera parte del capítulo 5 de mi tesis de Doctorado en Historia, dirigida por la Dra. Ana María Presta y defendida en la Facultad de Filosofía y Letras de la Universidad de Buenos Aires en marzo de 2012. Agradezco los comentarios y sugerencias de Roxana Boixados, Juan Pablo Ferreiro y Silvia Palomeque, miembros del jurado. Una versión preliminar de este trabajo fue presentada en el IV Simposio Internacional sobre Religiosidad, Cultura y Poder, Buenos Aires, 29 al 31 de agosto de 2012. Agradezco las advertencias complementarias que María Alba Bovisio me hiciera en aquella oportunidad, las cuales tuve en cuenta para la confección de esta nueva versión.

\section{Referencias citadas}

\section{Fuentes primarias}

Archivo y Biblioteca Nacionales de Bolivia (ABNB). Sucre, Bolivia.

Expedientes Coloniales (EC)

EC 1630-2. Los caciques de Laja contra los de Guaqui, sobre las tierras de Cantapa en Pacajes.

EC 1689-35. Diego Ortuño contra los indios de Caquingora sobre derecho a la estancia y tierras de Guallani en Pacajes.

Minas (Min)

Min 123-11. Don Gabriel Fernández Guarachi, indio, capitán general para el entero de la mita de Potosí en 1634, sobre los impedimentos que don Antonio Mogollón de Rivera, corregidor de La Paz, le opuso por sus particulares intereses al cumplimiento de dicha comisión en la provincia de Pacajes (1644-1634).

Archivo de la Curia Arzobispal de La Paz "Cngo. Felipe López Menéndez" (ACALP). La Paz, Bolivia.

Tomo 1 (1629-1643) 
Archivo General de La Nación (AGN). Buenos Aires, Argentina.

Sala XIII, Legajo 17-2-3. Padrones de indios. Omasuyos (1579-1684).

Sala XIII, Legajo 18-1-2. Padrones de indios. Pacajes (1683-1684)

Archivo de La Paz (ALP). La Paz, Bolivia.

Expedientes Coloniales (EC)

Caja 1 Expediente 32. Expediente que contiene el remate de las tierras entre la Ventilla, Hayo-Hayo y Sicasica (1594).

Colección «Gaspar García Viñas» de Copias de Documentos del Archivo General de Indias. Biblioteca Nacional, Buenos Aires, Argentina.

Tomo 189

\section{Fuentes segundarias}

ABERCROMBIE, T., 2006 [1998] - Caminos de la Memoria y del Poder. Etnografía e historia de una comunidad andina, 630 pp.; La Paz-Lima: Instituto de Estudios Bolivianos (IEB), Instituto Francés de Estudios Andinos (IFEA), Cooperación ASDI-SAREC.

ACUTO, F. A., 1999 - Paisaje y dominación: la constitución del espacio social en el imperio Inka. In: Sed Non Satiata. Teoría social en la arqueología latinoamericana contemporánea (A. Zarankin \& F. A. Acuto, eds.): 33-75; Buenos Aires: Ediciones del Tridente.

AMSELLE, J.-L., 1985 - Ethnies et espaces: pour une anthropologie topologique. In: Au Coeur de l'Ethnie : ethnies, tribalisme et Etat en Afrique (J.-L. Amselle \& E. M'Bokolo, eds.): 11-48; París: La Découverte.

BERTONIO, L., 1984 [1612] - Vocabulario de la Lengua Aymara, 946 pp.; Cochabamba: IFEA, Musef, Ceres.

BOURDIEU, P., 1982 [1976] - Algunas propiedades de los campos. In: Sociología y Cultura: 135-141; México: Grijalbo.

BOUYSSE-CASSAGNE, T., 1978 - L'espace aymara: urco et uma. Annales E.S.C., 33 (5-6): 1057-1080.

BOUYSSE-CASSAGNE, T., 2000 - Les mots, les morts et l'écriture: arts de la mémoire et évangelisation dans les Andes. Cahiers des Amériques Latines, 33: 57-84.

BOUYSSE-CASSAGNE, T., 2004 - El sol de adentro: wakas y santos en las minas de Charcas y el lago Titicaca (siglos XV a XVII). Boletín de Arqueología, 8: 59-97.

BOUYSSE-CASSAGNE, T., 2005 - Las minas del centro-sur andino, los cultos prehispánicos y los cultos cristianos. Bulletin de I'Institut Français d'Études Andines, 34 (3): 443462.

BOUYSSE-CASSAGNE, T. \& CHACAMA R., J., 2012 - Partición colonial del territorio, cultos funerarios y memoria ancestral en Carangas y precordillera de Arica (siglos XVIXVII). Chungara, 44 (4): 669-689.

CAÑEDO-ARGÜELLES FÁBREGA, T., 1993 - Potosí: la Versión Aymara de un Mito Europeo. La minería y sus efectos en las sociedades andinas del siglo XVII (La provincia de Pacajes), 127 pp.; Madrid: Catriel.

CAÑETE y DOMíNGUEZ, P., 1974 [c. 1771] - Código Carolino de Ordenanzas Reales de Minas de Potosí y demás Provincias del Río de la Plata. In: El Código Carolino de Pedro Vicente Cañete (E. Martiré, ed.); Buenos Aires: Universidad de Buenos Aires.

CARMAGNANI, M., 1988 - El Regreso de los Dioses. El proceso de reconstitución de la identidad étnica en Oaxaca. Siglos XVII y XVIII, 263 pp.; México: Fondo de Cultura Económica. 
CHOQUE CANQUI, R., 1993 - Sociedad y EConomía Colonial en el Sur Andino, 180 pp.; La Paz: Hisbol.

CHOQUE CANQUI, R., 2003 - Cinco siglos de historia, 390 pp.; La Paz: Plural-CIPCA. Serie Jesús de Machaqa: La marka rebelde 1.

CHRISTIAN, W. A., 1991 - Religiosidad Local en la España de Felipe II, 352 pp.; Madrid: Nerea.

COLE, J. A., 1985 - The Potosí Mita 1573-1700. Compulsory Indian labor in the Andes, xi + 206 pp.; Stanford: Stanford University Press.

COOK, N. D. (ed.), 1975 - Tasa de la Visita General de Francisco de Toledo, xliii + 341 s; Lima: Universidad Nacional Mayor de San Marcos.

CRUZ, P., 2006 - Mundos permeables y espacios peligrosos. Consideraciones acerca de punkus y qaqas en el paisaje altoandino de Potosí, Bolivia. Boletín del Museo Chileno de Arte Precolombino, 11 (2): 35-50.

CRUZ, P., 2009 - Huacas olvidadas y cerros santos. Apuntes metodológicos sobre la cartografía sagrada en los Andes del sur de Bolivia. Estudios Atacameños, 38: 55-74.

DECOSTER, J.-J. (ed.), 2002 - Incas e Indios Cristinanos. Elites indígenas e identidades cristianas en los Andes coloniales, 496 pp.; Cuzco: Instituto Francés de Estudios Andinos (IFEA), Centro Bartolomé de Las Casas (CBC).

DEL RÍO, M., 2005 - Etnicidad, Territorialidad y Colonialismo en los Andes: Tradición y cambio entre los soras de los siglos XVI y XVII, 341 pp.; La Paz-Lima: Instituto de Estudios Bolivianos (IEB), Instituto Francés de Estudios Andinos (IFEA).

DUVIOLS, P., 1976a - Un symbolisme andin du double : la lithomorphose de l'ancêtre. In: Actes du XLII Congrès International des Américanistes, VI: 359-364; París, 2 al 9 de septiembre.

DIVIOLS, P., 1976b - La capacocha. Allpanchis Puthurinqa, 9: 11-58.

DUVIOLS, P., 1986 - Cultura Andina y Represión. Procesos y visitas de idolatrías y hechicerías, Cajatambo, siglo XVII, Ixxxvi + 570 pp.; Cuzco: Centro Bartolomé de Las Casas.

ESTENSSORO FUCHS, J. C., 2003 - Del Paganismo a la Santidad. La incorporación de los indios del Perú al catolicismo. 1532-1750, 586 pp.; Lima: Pontificia Universidad Católica del Perú (PCUP) - Instituto Francés de Estudios Andinos (IFEA).

FARRIS, N., 1992 [1984] - La Sociedad Maya bajo el Dominio Colonial. La empresa colectiva de la supervivencia, 653 pp.; Madrid: Alianza.

GIL GARCÍA, F. M., 2001 - Secuencia y consecuencia del fenómeno chullpario. En torno al proceso de semantizacion de las Torres Chullpa. Anales del Museo de América, 9: 165-199.

GONZÁLEZ HOLGUÍN, D., 2007 [1608] - Vocabulario de la Lengua General de todo el Perú Ilamada Lengua Qquichua o del Inca, Runasimipi Qespisqa Software, www. runasimipi.org

HALBWACHS, M., 1950 - La Mémoire Collective, 105 pp.; París: PUF.

HAMPE MARTíNEZ, T., 1979 - Relación de los encomenderos y repartimientos del Perú en 1561. Historia y Cultura, 12: 75-117.

HARRIS, O. \& BOUYSSE-CASSAGNE, T., 1987 - Pacha: en torno al pensamiento aymara. In: Tres Reflexiones sobre el Pensamiento Andino: 11-59 (T. Bouysse-Cassagne et al., eds.); La Paz: Hisbol.

KESSELI, R. \& PÄRSSINEN, M., 2005 - Identidad étnica y muerte: torres funerarias (chullpas) como símbolos de poder étnico en el altiplano boliviano de Pakasa (1250-1600 d. C.). Bulletin de l'Institut Français d'Études Andines, 34 (3): 379-410. 
LOWENTAL, D., 1975 - Past time, present place: landscape and memory. The Geographical Review, 55 (1): 1-36.

MacCORMACK, S., 1991 - Religion in the Andes. Vision and Imagination in Early Colonial Peru, $x v+488$ pp.; Princeton, N.J.: Princeton University Press.

MacCORMACK, S., 2001 - History, historical record, and ceremonial action: Incas and Spaniard in Cuzco. Comparative Studies in Society and History, 43 (2): 329-363.

MARTíNEZ CERECEDA, J. L., 1995 - Autoridades en los Andes, los Atributos del Señor; Lima: Pontificia Universidad Católica del Perú (PUCP).

MORRONE, A. J., 2010a - Legitimidad, genealogía y memoria en los Andes meridionales: los Fernández Guarachi de Jesús de Machaca (Pacajes, siglos XVI-XVII). Memoria Americana. Cuadernos de Etnohistoria, 18 (2): 211-237.

MORRONE, A. J., 2010b - Clero rural y liderazgo étnico en el corregimiento de Pacajes: la antigua iglesia de Jesús de Machaca (siglo XVII). Anuario de Estudios Bolivianos, Archivísticos y Bibliográficos, 16: 445-475.

MORRONE, A. J., 2012 - Conforme es el cacique asi esta cada pueblo. Trayectorias de liderazgo étnico y legitimidad en los Andes Meridionales: Pacajes y Omasuyos (siglos XVI-XVII); Universidad de Buenos Aires: Facultad de Filosofía y Letras. Tesis de Doctorado en Historia.

MURRA, J. V., 1999 [1978] - La Organización Económica del Estado Inca, 270 pp.; México: Siglo XXI.

ONDEGARDO, P., 1990 [1571] - Relación de los Fundamentos del Notable Daño que Resulta de No Guardar a los Indios sus Fueros, 173 pp.; Laura González y Alicia Alonso eds. Madrid: Historia 16.

PÄRSSINEN, M., 2005 - Caquiaviri y la Provincia Pacasa. Desde el alto-formativo hasta la conquista española (1-1533), xvii + 318 pp.; La Paz: Producciones CIMA.

PLATT, T., BOUYSSE-CASSAGNE, T. \& HARRIS, O., 2006 - Qaraqara-Charka. Mallku, Inka y Rey en la provincia de Charcas (siglos XV-XVII). Historia antropológica de una confederación aymara, 1088 pp.; La Paz: Instituto Francés de Estudios Andinos (IFEA), Plural.

QUEREJAZU ESCOBARI, L., 2011 - Cielo/Infierno/Tentación. La muerte en Caquiaviri. In: Entre cielos e infiernos. Memoria del V Encuentro Internacional sobre Barroco: 271-278; Pamplona: Fundación Visión Cultural-Servicio de Publicaciones de la Universidad de Navarra.

RAMíREZ, S. E., 2005 - To Feed and Be Fed. The cosmological bases of authority and identity in the Andes, $\mathrm{x}+358$ pp.; Standford: Stanford University Press.

RAMíREZ del ÁGUILA, P., 1978 [1639] - Noticias Políticas de Indias; Sucre: Imprenta de la Universidad.

RAMOS, G., 2010 - Muerte y Conversión en los Andes. Lima y Cuzco, 1532-1670, 362 pp.; Lima: Instituto de Estudios Peruanos (IEP), Instituto Francés de Estudios Andinos (IFEA).

RAMOS GAVILÁN, Fr. A., 1976 [1621] - Historia de Nuestra Señora de Copacabana, ix + 257 pp.; La Paz: Academia Boliviana de la Historia.

RANDALL, R., 1993 - Los dos vasos. Cosmovisión y política de la embriaguez desde el inkanato hasta la colonia. In: Borrachera y Memoria. La experiencia de lo sagrado en los Andes (T. Saignes, comp.): 73-112; La Paz-Lima: Hisbol, Instituto Francés de Estudios Andinos (IFEA). 
ROSTWOROWSKI, M., 2003 - Peregrinaciones y procesiones rituales en los Andes. Journal de la Societé des Américanistes, 89 (2): 97-123.

SACK, R. D., 1986 - Human Territoriality. Its theory and history, xi + 256 pp.; Cambridge: Cambridge University Press.

SAIGNES, T., 1987 - De la borrachera al retrato: los caciques andinos entre dos legitimidades (Charcas). Revista Andina, 5 (1): 130-170.

SÁNCHEZ ALBORNOZ, N., 1978 - Indios y Tributos en el Alto Perú, 224 pp.; Lima: Instituto de Estudios Peruanos (IEP).

SANHUEZA TOHÁ, C., 2004 - Medir, amojonar, repartir: territorialidades y prácticas demarcatorias en el camino incaico de Atacama (II Región, Chile). Chungara. Revista de Antropología Chilena, 36 (2): 483-494.

SENDÓN, P. F., 2010 - Ch'ullpa y sociedades de pastores en los Andes centrales y meridionales (siglos XIX y XX): una propuesta. Población \& Sociedad, 17: 95-145.

STERN, S. J., 1986 [1982] - Los Pueblos Indígenas del Perú y el Desafío de la Conquista Española. Huamanga hasta 1640, 358 pp.; Madrid: Alianza.

TANDETER, E., 1992 - Coacción y Mercado. La minería de la plata en el Potosí Colonial, 1692-1826, 332 pp.; Buenos Aires: Sudamericana.

TAYLOR, G., 1974-1976 - Camay, camac et camasca dans le Manuscrit quechua de Huarochirí. Journal de la Societé des Américanistes, 63: 231-244.

TAYLOR, W. B., 2000 - La Iglesia entre la jerarquía y la religión popular: mensajes de la zona de contacto. In: Historia de América Latina (B. F. Connaughton, ed.): I, 177226; México: Universidad Nacional Autónoma de México (UNAM).

TORRES de MENDOZA, L. (dir.), 1865 - Colección de Documentos Inéditos Relativos al Descubrimiento, Conquista y Colonización de las Posesiones Españolas en América y Oceanía, 42 volúmenes; Madrid: Imprenta de Frías y Compañía.

WACHTEL, N., 2001 [1990] - El Regreso de los Antepasados. Los indios urus de Bolivia, del siglo XX al XVI, 648 pp.; México: Fondo de Cultura Económica. 